\title{
LAND COVER MAPPING USING SENTINEL-1 SAR DATA
}

\author{
S. Abdikan ${ }^{\mathrm{a},{ }^{*}}$, F.B. Sanli ${ }^{\mathrm{b},}$, M. Ustuner ${ }^{\mathrm{b}}$, F. Calò ${ }^{\mathrm{c}}$ \\ a,* Department of Geomatics Engineering, Bulent Ecevit University, 67100 Zonguldak, Turkey - sabdikan@beun.edu.tr \\ ${ }^{\mathrm{b}}$ Department of Geomatics Engineering, Yildiz Technical University, 34220 Esenler-Istanbul, Turkey \\ (fbalik, mustuner)@yildiz.edu.tr \\ ${ }^{\mathrm{c}}$ National Research Council (CNR) of Italy - Istituto per il Rilevamento Elettromagnetico dell'Ambiente (IREA), Diocleziano 328 , \\ 80124 Napoli, Italy - calo.f@irea.cnr.it
}

\section{ThS3: Sentinel-I Radar}

KEY WORDS: Sentinel-1A, Synthetic Aperture Radar, Land cover classification, Support Vector Machines, Istanbul, Turkey

\begin{abstract}
:
In this paper, the potential of using free-of-charge Sentinel-1 Synthetic Aperture Radar (SAR) imagery for land cover mapping in urban areas is investigated. To this aim, we use dual-pol $(\mathrm{VV}+\mathrm{VH})$ Interferometric Wide swath mode (IW) data collected on September 16th 2015 along descending orbit over Istanbul megacity, Turkey. Data have been calibrated, terrain corrected, and filtered by a $5 \times 5$ kernel using gamma map approach. During terrain correction by using a $25 \mathrm{~m}$ resolution SRTM DEM, SAR data has been resampled resulting into a pixel spacing of 20m. Support Vector Machines (SVM) method has been implemented as a supervised pixel based image classification to classify the dataset. During the classification, different scenarios have been applied to find out the performance of Sentinel-1 data. The training and test data have been collected from high resolution image of Google Earth. Different combinations of VV and VH polarizations have been analysed and the resulting classified images have been assessed using overall classification accuracy and Kappa coefficient. Results demonstrate that, combining opportunely dual polarization data, the overall accuracy increases up to $93.28 \%$ against $73.85 \%$ and $70.74 \%$ of using individual polarization VV and $\mathrm{VH}$, respectively. Our preliminary analysis points out that dual polarimetric Sentinel-1SAR data can be effectively exploited for producing accurate land cover maps, with relevant advantages for urban planning and management of large cities.
\end{abstract}

\section{INTRODUCTION}

Land cover maps are essential as a source of practical information for many purposes such as natural environment (Ullmann et al., 2014), biodiversity (Falcucci et al., 2007), urbanization (Geymen and Baz 2008, Liu and Wang 2013), agriculture (Bargiel and Herrmann 2011) and hazard assessment (van der Sande et al 2003).

Developments in Remote Sensing technology provides a large number of Earth observation satellites by which enabling of monitoring the Earth surface dynamics. Due to sudden and unexpected natural hazards, global climate change and population growth as well as protection and management of natural sources are becoming privileged topics for many countries.

Many studies investigated the efficient utilize of remote sensing data for both local and global scale thematic characterization for land cover analyses (Friedl et al. 2010). Moreover, remotely sensed images can be utilized monitoring of land cover consistently and continuously to identify spatial distribution land cover changes over the large areas (Congalton et al. 2014).

Synthetic Aperture Radar (SAR) images are utilized especially when meteorological conditions are not suitable for acquirement of optical data. Contrary to optical satellites, SAR satellites can provide cloud-free images (Balzter et al 2015). SAR data has been investigated in several studies and proven that it is effective for land cover monitoring (Longepe et al., 2011, Niu and Ban 2013, Balzter et al., 2015).

Image classification methods are widely used to extract information from the images to identify land cover types regarding to pixel values of the image. Analysis on dual orbit multi-temporal and full polarimetric RADARSAT-2 was carried out for land cover mapping by Niu and Ban (2013). They used intensity information with polarimetric parameters to increase the accuracy of land cover classification. Baltzer et al. (2015) performed two Sentinel-1A satellite data and SRTM digital elevation (DEM) data for the European CORINE land cover mapping. They reached almost $70 \%$ classification accuracy using dual polarimetric data, texture with DEM and DEM related product such as slope, aspect.

SVM is a widely used machine learning algorithm and popular in remote sensing by providing high classification accuracy while using small training data set (Melgani and Bruzzone, 2004, Mountrakis et al., 2011).

In this paper we investigated Istanbul megacity which has more than 15 million population. Rapid industrialization significantly increased the population of the city. Consequently, some land cover of the study area such as agriculture and forest were transformed into urban class (Geymen and Baz 2008, Sertel et al., 2010).

Our previous studies reported that Istanbul suffers from deformation phenomena due to its geological structure and human activities. Surface deformations were reached up to 4-5 
cm/year using TerraSAR-X data at densely urbanized and populated area (Calo et al., 2015). Thus, high accuracy of land cover mapping is essential for the planning and management of urban. Detection of accurate land cover is very important for such a megacity to monitor the changes, to understand the impacts on climate and future predictions. In order to support the rapid mapping of land cover for decision makers' up-to-date information is crucial.

This paper aims to evaluate the Sentinel-1A imagery for the land cover mapping using amplitude information of dual polarimetric SAR imagery.

\section{STUDY AREA AND DATA USED}

The study area is located in Istanbul province at northwest of Turkey. Having ca. 15 million inhabitants Istanbul is also one of the most important megacities in the world. It is the financial and commercial capital of Turkey. While, the province has sides at both Asia and Europe, in this study we focused on European side (Figure 1). Due to its location, Istanbul has borderline among Mediterranean, humid and subtropical climate.
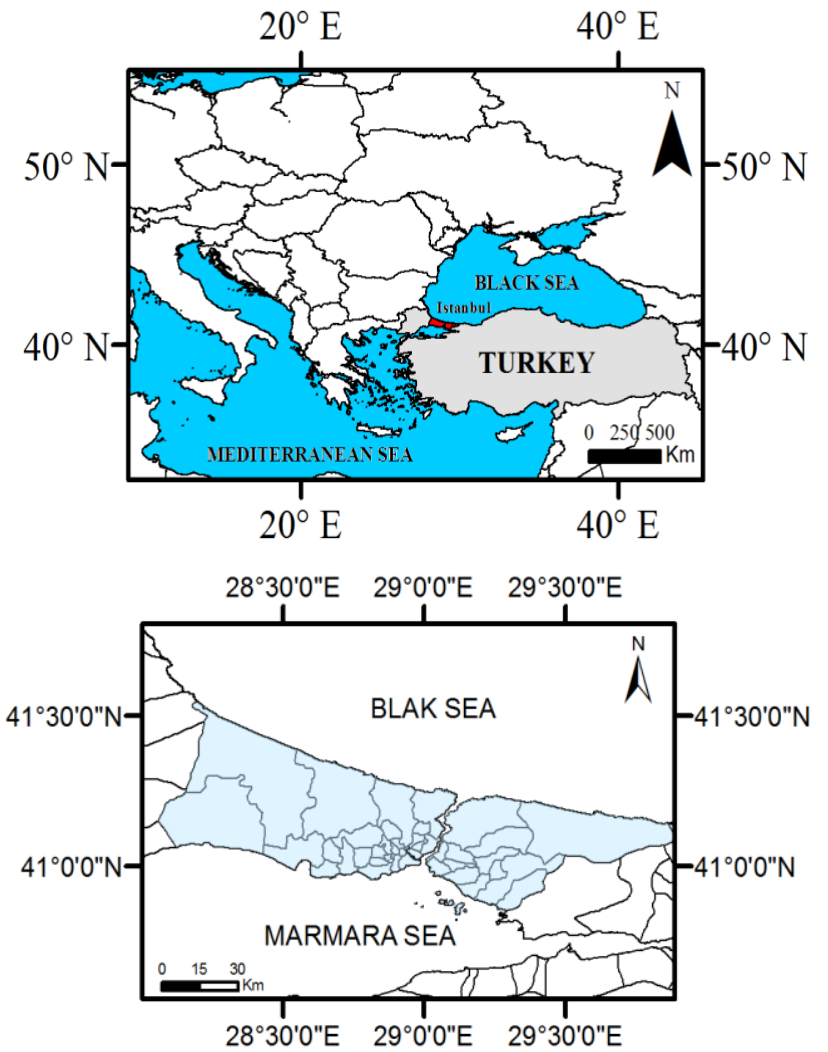

Figure 1. Study Site

The northern part of the area is bordered with Black Sea and the east of the area has coastline of Bosporus which is a natural border between Europe and Asia. Northern part where vegetation and forest have higher densities has characteristics of ocean and humid subtropical climate. The population is higher at the South of the area dominated by agriculture and it is under the influence of warmer and drier air according to being Mediterranean climate.
The European Space Agency (ESA) launched one of the constellation of two radar satellite Sentinel-1A in April 2014. Sentinel satellite provides C-band images in both singular and dual polarization within 12 days of repeat cycle. The data is free of charge for all users which makes it more attractive for new challenging applications and opportunities (Nagler et al., 2015). It can acquire images in three acquisition modes as Stripmap (SM), Interferometric Wide Swath (IW), Extra Wide Swath (EW) and Wave (WV) with different processing levels.

In this paper, single date Level-1 Ground Range Detected (GRD) product of Sentinel was used. SAR image of Sentinel was acquired in September 16th 2016 over Istanbul city. The GRD data has been multi-looked and projected to ground range using Earth ellipsoid model. A composite image of study area is shown in Figure 2 using $\mathrm{VV}, \mathrm{VH}$ and difference of two polarimetry $(\mathrm{VV}-\mathrm{VH})$ data. The specifications of the data is given in Table 1.

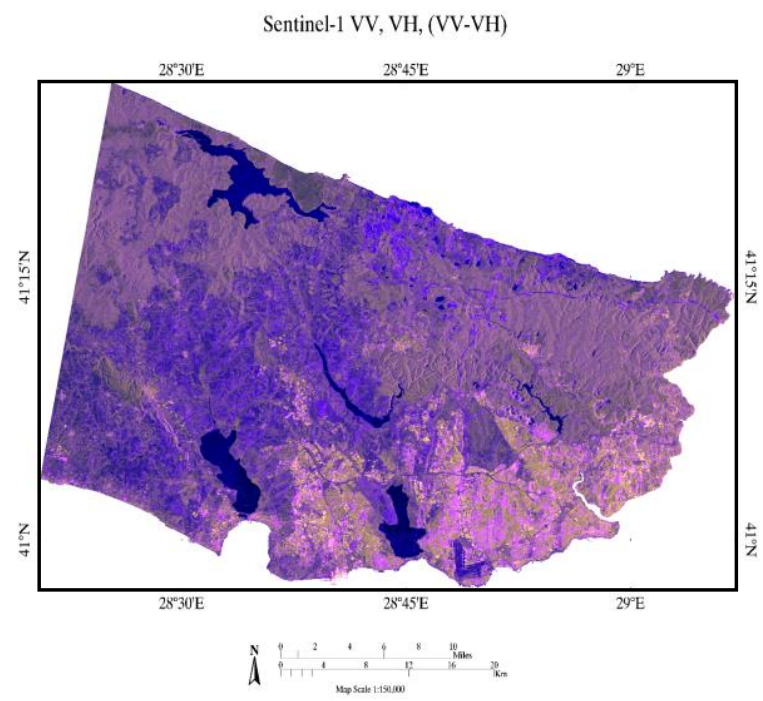

Figure 2. Composite image of Sentinel VV, VH, (VV-VH)

\begin{tabular}{|l|l|}
\hline Specifications & Sentinel-1A data \\
\hline Acquisition time & September 16th 2015 \\
\hline Acquisition orbit & Descending \\
\hline Imaging Mode & IW \\
\hline Imaging frequency & C-band (5.4GHz) \\
\hline Polarization & VV-VH \\
\hline Data product & Level-1 GRD \\
\hline Resolution mode & $20 \mathrm{~m}$ (Full resolution) \\
\hline
\end{tabular}

Table 1. Specifications of Sentinel-1A data

\section{METHODOLOGY}

\subsection{Pre-processing}

The Level-1 product of Sentinel-1 GRD data is calibrated, filtered by a 5 X 5 kernel using gamma map approach and terrain corrected before application. During terrain correction a $25 \mathrm{~m}$ SRTM data has been used and the data was resampled to a pixel size of $20 \mathrm{~m}$ ground resolution. The digital numbers values (DN) of SAR data is converted into backscattering values in decibel (db) scale. Pre-processing was conducted using ESA 
Sentinel-1 toolbox (S1TBX) in the Sentinel Application Platform provided by ESA.

\subsection{Image Classification}

Supervised SVM classification method has been implemented for mapping land cover types. As a machine learning algorithm, support vector machines have been widely used and tested many times in remote sensing in both optical and radar data for image classification (Niu and Ban 2013, Abdikan et al., 2015, Ustuner et al 2015). The principle of SVM is to define an optimal hyperplane to maximize margin width by using training subset (Mountrakis et al. 2011). In this study, Radial Basis Function (RBF) as a kernel type was implemented as an efficient function (Kavzoglu and Colkesen, 2009) and optimum parameters were determined as 0.333 and 100 for kernel width and penalty parameter, respectively. Further details of method could be found in Mountrakis et al. (2011). Kappa statistics and overall accuracy assessment was applied to compare the accuracy of classified images Ground truth and test data were collected from high resolution images of Google Earth (Table 2).

\begin{tabular}{|l|c|c|}
\hline Classes & Training & Validation \\
\hline Water (inland water, lakes) & 220 & 835 \\
\hline $\begin{array}{l}\text { Urban (settlements, } \\
\text { artificial, industry) }\end{array}$ & 178 & 1029 \\
\hline Forest (pure and mixed) & 164 & 1216 \\
\hline $\begin{array}{l}\text { Agriculture (cultivated, } \\
\text { uncultivated) }\end{array}$ & 106 & 661 \\
\hline $\begin{array}{l}\text { Bareland (bare fields, } \\
\text { mining) }\end{array}$ & 74 & 408 \\
\hline
\end{tabular}

Table 2.Training set size

For the utilization from dual polarimetric data of Sentinel-1 different cases were defined and each of them was classified to achieve high classification accuracy.

\begin{tabular}{|c|c|l|}
\hline Scenario & No of variables & Description of variables \\
\hline 1 & 1 & $\mathrm{VV}$ \\
\hline 2 & 1 & $\mathrm{VH}$ \\
\hline 3 & 1 & $(\mathrm{VV}+\mathrm{VH}) / 2$ \\
\hline 4 & 2 & $\mathrm{VV}, \mathrm{VH}$ \\
\hline 5 & 3 & $\mathrm{VV}, \mathrm{VH}, \mathrm{VV} / \mathrm{VH}$ \\
\hline 6 & 3 & $\mathrm{VV}, \mathrm{VH},(\mathrm{VV}+\mathrm{VH}) / 2$ \\
\hline 7 & 3 & $\mathrm{VV}, \mathrm{VH},(\mathrm{VV}-\mathrm{VH})$ \\
\hline 8 & 5 & $\begin{array}{l}\mathrm{VV}, \mathrm{VH},(\mathrm{VV}-\mathrm{VH}),(\mathrm{VV} / \mathrm{VH}), \\
(\mathrm{VV}+\mathrm{VH}) / 2\end{array}$ \\
\hline
\end{tabular}

Table 3. Dataset of experiments for land cover classification

\section{RESULTS AND DISCUSSION}

In the experimental analysis eight scenario was defined for image classification, and impact of variables was evaluated. First, each polarimetry was classified as single variable and the results show that VV polarimetry has slightly higher accuracy than VH polarimetry (Figure 3).

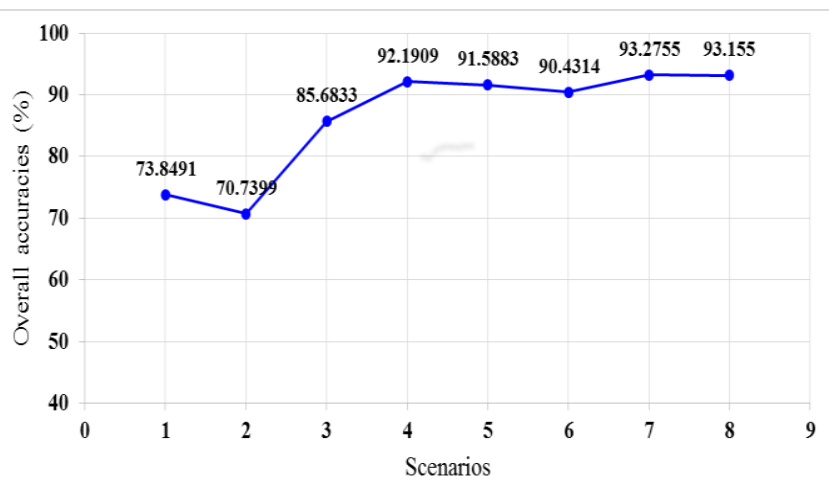

Figure 3. SVM classification accuracies with different variables

Using dual polarimetry dramatically increased the accuracy of image classification (Figure 3). The results of the image classification of $\mathrm{VH}$ with lowesst accuracy and combination of $\mathrm{VV}$ and VH are shown in Figure 4 and Figure 5 respectively. The water class is extracted clearly when using even only one variable as VH image (Figure 1). However, it failed for the extraction of urban class. Especially at hilly parts of the study area misclassification is visible.

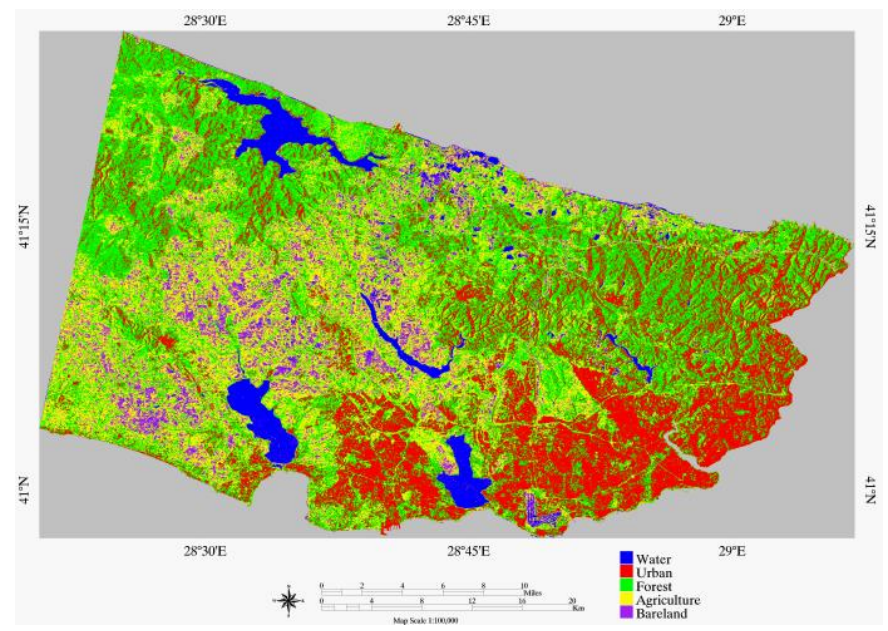

Figure 4. Classification result of VH image.

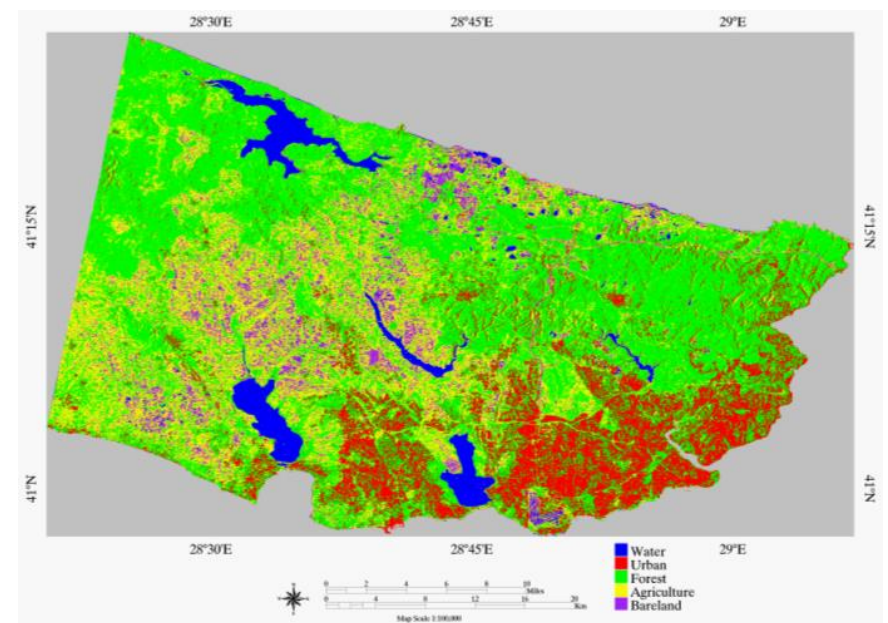

Figure 5. Classification result of VV,VH image. 


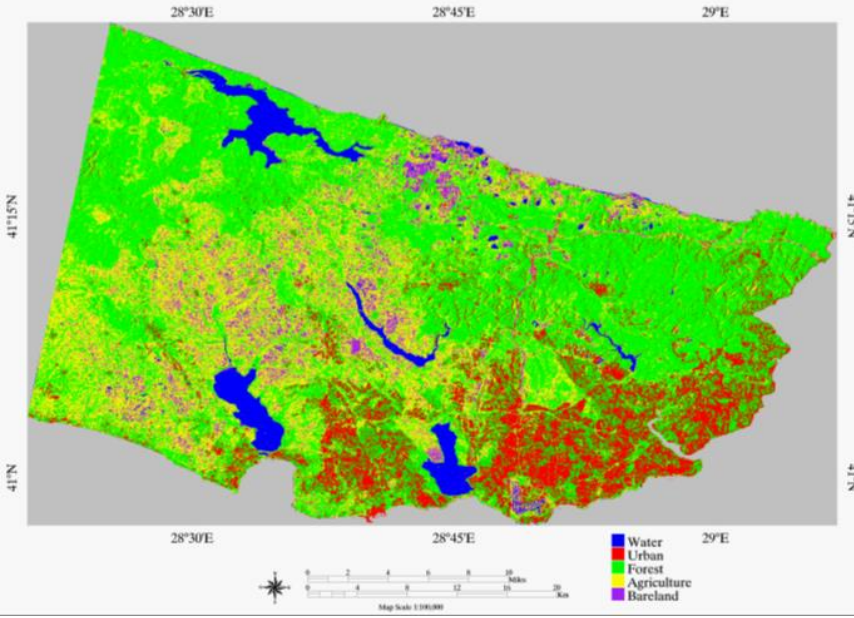

Figure 4. Classification result of VV,VH, (VV-VH) image.

Using more than one variable significantly increased the classification accuracy. Especially scenarios 7 and 8 has higher accuracies than other scenarios with $93.2755 \%$ and $93.1550 \%$ respectively.

\section{CONCLUSIONS}

In this study, the performance of Sentinel-1 imagery was under investigation. It is aimed to figure out the potential of using only SAR imagery over a complex megacity. To enhance the accuracy of image classification results, various variables are created by dual polarimetric data and different scenarios were tested.

Experimental results indicated that different scenarios provided different results according to corresponding variables. Using difference imagery $(\mathrm{VV}-\mathrm{VH})$ as a third variable into the classification resulted in higher accuracy than mean and ratio variables. The results emphasize the critical importance of using different variables in the image classification.

It is noticed that the outputs of this study have promising results for multi-temporal monitoring for long term analysis. After the launch of Sentinel-1B the revisit time is going to be 6 days of systematic image acquisition which may provide frequent information for a detailed analysis especially for land cover of vegetation and agricultural areas.

The preliminary results indicate that dual polarized IW Sentinel-1A is suitable for rapid land cover extraction through using SAR images. The results of the study may reference for further analysis of Sentinel-1 data over large and complicated mega cities. As further research, texture measures are going to be integrated for the evaluation of land cover analysis.

\section{REFERENCES}

Abdikan, S., Bilgin, G., Sanli, F.B., Uslu, E., Ustuner, M., 2015. Enhancing land use classification with fusing dualpolarized TerraSAR-X and multispectral RapidEye data Journal of Applied Remote Sensing, 9 (1), 096054.

Balzter, H., Cole, B., Thiel, C., Schmullius, C., 2015. Mapping CORINE Land Cover from Sentinel-1A SAR and SRTM Digital Elevation Model Data using Random Forests. Remote Sensing, 7, pp. 14876-14898.
Bargiel, D., Herrmann, S., 2011. Multi-Temporal Land-Cover Classification of Agricultural Areas in Two European Regions with High Resolution Spotlight TerraSAR-X Data. Remote Sensing, 3, pp. 859-877.

Congalton, R.G., Gu, J., Yadav, K., Thenkabail, P., and Ozdogan M., 2014. Global Land Cover Mapping: A Review and Uncertainty Analysis, Remote Sensing, 6, pp. 12070-12093.

Falcucci, A., Maiorano, L., Boitani L., 2007. Changes in landuse/land-cover patterns in Italy and their implications for biodiversity conservation, Landscape Ecology April 2007, Volume 22, Issue 4, pp 617-631.

Friedl, M.A., Sulla-Menashe, D., Tan, B., Schneider, A., Ramankutty, N., Sibley, A., Huang, X., 2010. MODIS Collection 5 global land cover: Algorithm refinements and characterization of new datasets. Remote Sensing of Environment, 114, pp. 168-182.

Geymen, A. and Baz, I., 2008. Monitoring urban growth and detecting land-cover changes on the Istanbul metropolitan area, Environ Monit Assess, 136, pp. 449-459.

Kavzoglu, T., and Colkesen, I., 2009. A kernel functions analysis for support vector machines for land cover classification. International Journal of Applied Earth Observation and Geoinformation, 11, pp. 352-359.

Liu H. and weng Q., 2013. Landscape metrics for analysing urbanization-induced land use and land cover changes. Geocarto International, 28(7): 582-593.

Longepe, N., Rakwatin, P., Isoguchi, O., Shimada, M., Uryu, Y., Yulianto, K., 2011. Assessment of ALOS PALSAR $50 \mathrm{~m}$ Orthorectified FBD Data for Regional Land Cover Classification by Support Vector Machines, IEEE Transactions on Geoscience and Remote Sensing, 49(6), pp. 2135-2150.

Nagler, T., Rott, H., Hetzenecker, M., Wuite, J., Potin, P., 2015. The Sentinel-1 Mission: New Opportunities for Ice Sheet Observations. Remote Sensing, 7, pp. 9371-9389.

Niu, X. and Ban, Y., 2013. Multi-temporal RADARSAT-2 polarimetric SAR data for urban land-cover classification using an object-based support vector machine and a rule-based approach, International Journal of Remote Sensing, 34, pp. 126.

Ullmann, T., Schmitt, A., Roth, A., Duffe, J., Dech, S., Hubberten, H.-W., Baumhauer, R., 2014. Land Cover Characterization and Classification of Arctic Tundra Environments by Means of Polarized Synthetic Aperture X- and C-Band Radar (PolSAR) and Landsat 8 Multispectral Imagery — Richards Island, Canada. Remote Sensing, 6, pp. 8565-8593.

Mountrakis, G., Im J., Ogole, C. 2011. Support vector machines in remote sensing: A review. ISPRS J. of Photogramm. and Remote Sens. 66, pp. 247-259.

Melgani, F., and Bruzzone, L., 2004. Classification of hyperspectral remote sensing images with support vector 
machines. IEEE Transactions on Geoscience and Remote Sensing, 42, pp. 1778-1790

Sertel E., Robock A., Ormeci C., 2010. Impacts of land cover data quality on regional climate simulations, International Journal of Climatology, 30, pp. 1942 - 1953.

Ustuner, M., Sanli, F.B., Barnali, D., 2015. Application of Support Vector Machines for Land Use Classification Using High-Resolution RapidEye Images: A Sensitivity Analysis, European Journal of Remote Sensing, 48, pp. 403-422.

Van der Sande, C.J., de Jong, S.M., de Roo, A.P.J., 2003. A segmentation and classification approach of IKONOS-2 imagery for land cover mapping to assist flood risk and flood damage assessment, International Journal of Applied Earth Observation and Geoinformation, 4(3), pp. 217-229. 